Supporting information

for

\title{
Synthesis of hydroxyapatite nanoparticles from phosphorus recovered from animal wastes
}

Gulcin U. Tosun, Yuriy Sakhno, and Deb P. Jaisi*

Harker Interdisciplinary Science and Engineering Laboratory, Department of Plant and Soil

Sciences, 221 Academy Street, University of Delaware, Newark, DE, 19716

* Corresponding author:

Deb P. Jaisi, Email: jaisi@udel.edu, Phone: (302)831-1376

Number of Pages: 4

Number of Figures: 0

Number of Tables: 3 
Table S1. Elemental compositions of the animal wastes.

\begin{tabular}{llllll}
\hline \multicolumn{1}{c}{ Elements } & $\begin{array}{c}\text { Chicken } \\
\text { litter }\end{array}$ & $\begin{array}{c}\text { Dairy } \\
\text { manure }\end{array}$ & $\begin{array}{c}\text { Horse } \\
\text { manure }\end{array}$ & $\begin{array}{c}\text { Sheep } \\
\text { manure }\end{array}$ & $\begin{array}{c}\text { Swine } \\
\text { manure }\end{array}$ \\
\hline Total nitrogen $(\%)$ & 3.8 & 3.5 & 1.4 & 2.1 & 4.7 \\
Total carbon (\%) & 36.5 & 42.9 & 44.1 & 45.7 & 41.5 \\
Carbon:nitrogen & 9.6 & 12.2 & 32.4 & 21.4 & 8.8 \\
Aluminum (mg/kg) & 209.9 & 697.3 & 1394.6 & 548.0 & 1157.7 \\
Arsenic & $<2.0$ & $<2.0$ & $<2.0$ & $<2.0$ & $<2.0$ \\
Boron & 19.3 & 18.7 & 5.5 & 10.1 & 11.1 \\
Calcium & 77989.8 & 20922.9 & 5214.7 & 13626.8 & 46768.3 \\
Cadmium & $<1.0$ & $<1.0$ & $<1.0$ & $<1.0$ & $<1.0$ \\
Cobalt & $<1.0$ & 4.7 & $<1.0$ & $<1.0$ & 1.3 \\
Chromium & 2.1 & 2.4 & 3.3 & 2.1 & 13.4 \\
Copper & 44.0 & 54.8 & 16.9 & 33.3 & 85.9 \\
Iron & 488.1 & 1250.3 & 1344.9 & 597.8 & 2418.3 \\
Potassium & 15865.9 & 4475.5 & 5231.2 & 7841.7 & 11071.6 \\
Magnesium & 7204.2 & 11028.4 & 2849.4 & 5034.4 & 12261.6 \\
Manganese & 529.8 & 254.2 & 261.7 & 215.0 & 345.4 \\
Sodium & 3474.3 & 2200.5 & 555.5 & 1007.8 & 571.3 \\
Nickel & 3.3 & 3.2 & 2.5 & 2.0 & 9.8 \\
Phosphorus & 12776.8 & 9780.2 & 2973.3 & 5908.7 & 35119.5 \\
Lead & 7.0 & 3.4 & 6.0 & 4.2 & 2.0 \\
Sulphur & 4959.0 & 3873.0 & 1689.9 & 2724.0 & 4558.7 \\
Zinc & 452.1 & 258.5 & 154.1 & 96.3 & 1062.9 \\
\hline & & & & & \\
\hline
\end{tabular}


Table S2. Elemental compositions of the animal waste extracts in $40 \mathrm{mM}$ citric acid. All concentrations are in PPM unless otherwise expressed.

\begin{tabular}{llllll}
\hline \multicolumn{1}{c}{ Elements } & $\begin{array}{c}\text { Chicken } \\
\text { litter }\end{array}$ & $\begin{array}{c}\text { Dairy } \\
\text { manure }\end{array}$ & $\begin{array}{c}\text { Horse } \\
\text { manure }\end{array}$ & $\begin{array}{c}\text { Sheep } \\
\text { manure }\end{array}$ & $\begin{array}{c}\text { Swine } \\
\text { manure }\end{array}$ \\
\hline Aluminum $(\mathrm{mg} / \mathrm{L})$ & 0.74 & 4.12 & 2.63 & 1.10 & 33.63 \\
Arsenic & 0.03 & 0.04 & 0.00 & 0.00 & 0.03 \\
Boron & 0.55 & 0.53 & 0.12 & 0.28 & 0.33 \\
Calcium & 526.29 & 657.02 & 203.18 & 461.14 & 1263.14 \\
Cadmium & 0.00 & 0.00 & 0.00 & 0.00 & 0.00 \\
Cobalt & 0.01 & 0.09 & 0.01 & 0.01 & 0.01 \\
Chromium & 0.02 & 0.03 & 0.01 & 0.01 & 0.30 \\
Copper & 0.42 & 0.06 & 0.03 & 0.07 & 0.11 \\
Iron & 6.74 & 16.38 & 3.34 & 1.35 & 59.46 \\
Potassium & 605.27 & 158.64 & 190.61 & 334.84 & 449.59 \\
Magnesium & 189.07 & 393.38 & 88.82 & 190.67 & 485.34 \\
Manganese & 15.37 & 7.49 & 8.75 & 7.10 & 5.21 \\
Sodium & 133.74 & 87.76 & 22.71 & 43.29 & 21.21 \\
Nickel & 0.07 & 0.07 & 0.02 & 0.02 & 0.23 \\
Phosphorus & 430.45 & 261.01 & 70.24 & 159.79 & 984.78 \\
Lead & 0.01 & 0.05 & 0.03 & 0.04 & 0.01 \\
Sulphur & 104.13 & 27.53 & 6.05 & 15.39 & 23.28 \\
Zinc & 8.23 & 5.39 & 5.49 & 2.50 & 25.14 \\
\hline
\end{tabular}


Table S3. Elemental compositions of the animal waste extracts in 5.0 M nitric acid. All concentrations are in PPM unless otherwise expressed.

\begin{tabular}{lccccc}
\hline \multicolumn{1}{c}{ Elements } & $\begin{array}{c}\text { Chicken } \\
\text { litter }\end{array}$ & $\begin{array}{c}\text { Dairy } \\
\text { manure }\end{array}$ & $\begin{array}{c}\text { Horse } \\
\text { manure }\end{array}$ & $\begin{array}{c}\text { Sheep } \\
\text { manure }\end{array}$ & $\begin{array}{c}\text { Swine } \\
\text { manure }\end{array}$ \\
\hline Aluminum (mg/L) & 3.56 & 10.28 & 9.43 & 4.05 & 43.95 \\
Arsenic & 0.00 & 0.00 & -0.01 & -0.01 & 0.01 \\
Boron & 0.76 & 0.77 & 0.21 & 0.43 & 0.54 \\
Calcium & 3082.52 & 833.27 & 231.75 & 535.96 & 1718.12 \\
Cadmium & 0.01 & 0.01 & 0.01 & 0.01 & 0.03 \\
Cobalt & 0.02 & 0.17 & 0.02 & 0.02 & 0.04 \\
Chromium & 0.07 & 0.06 & 0.05 & 0.03 & 0.47 \\
Copper & 1.80 & 3.07 & 0.76 & 0.78 & 4.39 \\
Iron & 15.98 & 24.93 & 14.70 & 5.12 & 65.93 \\
Potassium & 609.72 & 208.67 & 177.13 & 313.90 & 456.10 \\
Magnesium & 268.29 & 402.81 & 98.11 & 189.87 & 492.56 \\
Manganese & 17.97 & 10.13 & 11.31 & 8.24 & 13.07 \\
Sodium & 131.91 & 68.84 & 21.21 & 39.85 & 23.65 \\
Nickel & 0.11 & 0.10 & 0.05 & 0.04 & 0.35 \\
Phosphorus & 460.18 & 325.21 & 92.68 & 180.99 & 1171.63 \\
Lead & 0.31 & 0.18 & 0.21 & 0.14 & 0.08 \\
Sulphur & 132.03 & 65.18 & 25.84 & 44.05 & 63.18 \\
Zinc & 13.66 & 10.78 & 7.50 & 4.03 & 40.20 \\
\hline
\end{tabular}

